Año XLIX. urtea

$124-2017$

Uztaila - abendua Julio - diciembre

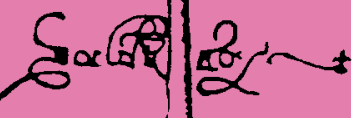
(t)

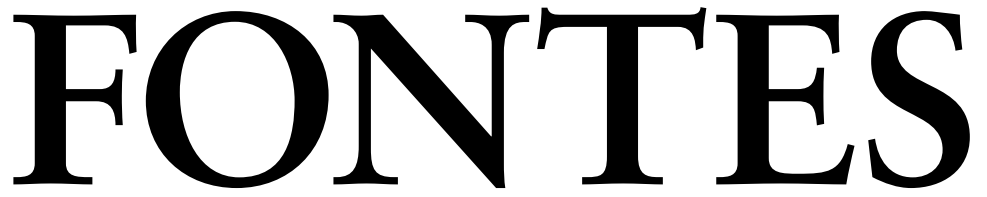

LINGVÆ

VASCONVM

STVDIA ET DOCVMENTA

SEPARATA

Axularren lantegian.

Iturbegi ezezaguna

Geroren lehen

kapituluaren bilbean

Patxi Salaberri MuñoA

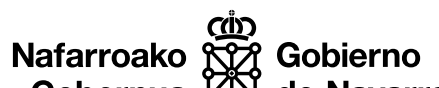

Gobernua \&S de Navarra 


\section{Axularren lantegian. Iturbegi ezezaguna Geroren lehen kapituluaren bilbean}

En el taller de Axular. Fuente desconocida en la trama del primer capítulo de Gero

At Axular's workshop. An unknown source in the plot of the first chapter of Gero

Patxi SALABERRI MUÑoA

Euskal Herriko Unibertsitatea, UPV/EHU

patxi.salaberri@ehu.eus 


\section{LABURPENA}

Axularrek berak aitortu bezala, Gero liburuan bada hainbat lerroalde garaiko deboziozko liburuetatik jasoak direnak. Ez ohi dira, halere, betegarri gisa tartekaturiko pasarteak, kapituluak zurkaizteko erabilitako teknika erretorikoaren tresna baizik. Iturburu-edo izan omen ziren horietako baten identifikazioa bide (Guzman, Bienes de el honesto trabajo, 1614), behin-behineko aletxoa ekartzen saiatu da honako artikulu hau, oraingo jolaslekua euskal idazlearen liburuaren lehen kapitulura mugatu bada ere. Hartara, Axularrek kapitulu osoa bilbatzeko erakutsitako eraz eta orain arte identifikatzeke zegoen iturbegi horretako pasarteen txertaketaz jardungo da bertan.

Gako hitzak: euskal literatura; Axular; Gero; erretorika; iturburuak.

\section{RESUMEN}

Tal como reconoció Axular, en el libro Gero hay diversos párrafos recogidos a partir de libros de culto de la época. Sin embargo, no suelen ser pasajes introducidos como mero relleno, sino herramientas de la técnica retórica para apuntalar los capítulos. Al hilo de identificar alguna de esas fuentes (Guzmán, Bienes de el honesto trabajo, 1614) este artículo ha intentado traer una muestra temporal, si bien es cierto que, en esta ocasión, el campo de acción se ha limitado al primer capítulo del escritor vasco. Así, se tratará sobre los modos de tejer un capítulo completo que empleaba Axular y de integrar los pasajes de esa fuente que estaba por identificar.

Palabras clave: literatura vasca; Axular; Gero; retórica; fuentes.

\section{ABSTRACT}

As Axular himself admits, in the Gero book there are some paragraphs taken from contemporary devotion books. They are not filler paragraphs, but elements at the service of the textual composition. Based on the identification of one of these sources (P. Guzman, Bienes de el honesto trabajo, 1614), this present article attempts to carry a provisional contribution, even if it is limited to the first chapter of the book. Thus, the article allows to appreciate the Axular's rhetorical way of organizing the cited chapter and introducing an until now unidentified source.

Keywords: Basque Literature; Axular; Gero; rhetoric; sources. 
et virgo non sum

San Kasiano

1. Aitzinaldea. 2. Bigarrena. 3. Hirugarrena. 4. Laugarrena. 5. Bosgarrena. 6. Seigarrena. 7. AZKentza. 8. Eranskina. 9. Erreferentziak.

\section{AITZINALDEA}

Arrisku handian ohi da, gaztetako tabakoaren antzera paper zaharrak ere behin betiko utziak dituela pentsatuz, haien artera mamurturik itzultzen dena, udaberri mordoxka bizkarreraturik duenaren kartapazio haustuen barnean beti dagoelako gogoratzen ez den zerbait, aiduru, ataizean bezala, begietara ausarki so, eta inork ez dakiela zergatik, lehen unean bertan espero baino askoz buruhauste gehiago sorraraztearekin -paper horiztatuen prosopopeia!- mehatxatzen duena.

Nik neuk ere, lasai bizitzen hasiko nintzela uste nuenean aurkitu nuen itxura inozoko kartapazio miragarri horietako sorta bat, zeharo ahaztua eta galdutzat nuena.

Aurreko batean aitortu nuen nork jarri zidan azken aldiz eskuetan, inongo erru(ki)rik gabe, idisko nafarra xaxatzeko akuilua, eta ez dut orain berriro haren izenik aipatuko, inork pentsa ez dezan nahi ez dudana leporatu nahi diodanik lagun zintzoari, baina egia da, dena den, harako hartan duela zezenketa-istorio amaigabe honek hasiera.

Eta kontua da, akuilua eskuan, aipatu kartapazio zaharrok irekitzean, iratxoen eran azaldu zela basidiskoa nire aurpegiaren aurrean, behinolako haur-ipuinetako kriseiluetatik ateratzen ziren haien antzera. Alabaina niri, ipuinetan ez bezala, desio kuttunez ase bainoago, eginkizunak eta betebeharrak ezarri zizkidan agertu bezain azkar.

Horietako bat da honako orrialde hauetan bete behar bide dudana: behiala Axularren testuaren atzetik burututako barrandari-lan baten aurkezpena eta hari buruzko hala-holako txostena. 


\section{BIGARRENA}

Aitortu dezadan aurren-aurrenik ez dutela lerrook sarrera berezirik eta ez aparatu kritiko edo aparteko teoriarik eskatzen, ez behintzat gainerako lanetan garatu izan dudanetik bereizi eta urrun litekeenik, Axularren urratsen atzetik ibili izanaren ondorio eta emaitza huts baitira oraingoan ere eranskin gisara lerrokaturik dakartzadanak.

Nolanahi ere, honetaz interesik duenak ildo bereko artikulura jo dezake, Torres jesuitaren Philosophia moral de principes delakoa ardatz izan genuen hartara, alegia (Salaberri, 2016). Gaurkoan, jakina, kartapazioetako beste autore bati egokituko zaio solasaldi-buru izatea.

Egia esan, aurreko espioitza-saialdiak berez bulkatzen ninduen artikulu luzeagoa -eta ondorioz, luzeegia- argitararaztera eta, hori zela eta, ezegoki iritzi nion, bestelakorik tartekatuz eta harako hura bukaezinago bilakaturik, ordukoak eta gaurkoak batera kaleratzeari.

Arrazoi -diogun- didaktikoak izan ziren, beraz, bikotea bakantzera eraman nindutenak, ongi asko ohartua bainintzen orduan eta ohartzen naiz orain ere Axularren lerroaldeok tratamendu integratuagoa eta osatuagoa beharko luketela haren jokamoldeak eta mailegatze-jolasak behar bezala atzeman ahal izateko.

Ez nuen orduan egin eta ez dut oraingoan egingo, horratik.

Irakurlearen eskuetan -edota balizko edizio komentatu baterako- utzi beharko da, hortaz, urdazubiarraren puzzlea bateratzeko eta osatzeko eginkizun hori.

Guk azken adreilu solteak besterik ez dugu ekarriko eraikuntza-lan erraldoi honetara, jadanik ahituta egoteaz gain, ez baikenuke inolaz ere nahi izango, nobela erdi beltz horietako batean detektibe euskaldun batek hilik agertu zen agure jubilatuaren zaletasunez zioen bezala, «lantzean behin, aldizkariren batean, matraka berdinaren inguruan» idatzitako artikuluak kaleratzen segitzea. Gizadiaren joaira ikusita, harako agure Gerozale hari gertatua gertatzeko arrisku bizia baikenuke apika geuk ere.

\section{HIRUGARRENA}

Oraingo honetan, esan legez, Axularrek Geroren lehen kapitulua osatzeko erabili bide zuen «etorria» dakargu mintzagai. Eta «etorri» horrek badu, ustez, izen-deiturarik (Pedro de Guzman), badu fede-mesfidantzak ezabatzeko moduko berme doktrinalik («calificador del Santo Officio de la Inquisición» da egilea) eta badu, baita ere 
-ezinbestekoa honetaratzeko-, idazlan argitaraturik: Bienes de el honesto trabajo y daños de la ociosidad en ocho discursos izenekoa (Madril, 1614) ${ }^{1}$.

Oro har, aurrekoan landu genuen Torresen Philosophia moral izeneko liburuaren garai bertsukoa da orrialdeotara dakargun obra aszetiko eta (aurre)kapitalista hau ${ }^{2}$ eta, are nabarmentzekoa dena, gaztelaniaren esparruko debozio-literaturari dagokio bete-betean.

Bereziki azpimarratu nahi genuke azken ezaugarri hori, zeren eta gero eta argiago geratzen ari baita aspaldiko hipotesi hura, hots, garbiki zioena Axularrek joera gehiago erakusten zuela Iberia aldeko erromantze nagusian idatzitako liburuetarako, latinezko eta frantsesezkoetarako baino. Dela ikasketetako hizkuntza nagusia arras barneratua zuelako, dela Teologia-batxilergoa burutzean horrelako bibliografiarako joerak eta bideak irekita geratu zitzaizkiolako, kontua da Axularren baranoan orain arte azaldutako «eragile» behinenak gaztelaniaren errepublikakoak direna. Hor ditugu horren lekuko Granada, Torres, zertxobait Alvarado, oraingoan Guzman...

Euskararen eremuko eragileak, ezaguna da, nekez izan zitezkeen izan zirenak baino askoz gehiago eta handiago, literatur erreferentziak gutxi -eta orduko irakurle gehienek ongi ezagunak- edukitzean, larregizkoa zatekeen haietaz baliatzen aritzea eta intertestualitate-ariketatan jardutea. Hortik, beraz, Materreren presentzia lausoa (eta urria, edonola ere), tantakako Leizarragarena (are urriagoa) eta, guk dakigula, deus gehiagorik ez (Salaberri, 2000).

\section{LAUGARRENA}

Gero liburuaren lehen kapitulua eta, orain arte ezezaguna genuen testu-iturri berri batez baliatuz, haren osaketa-prozesua ditugu artikulu honen xedea. Ez dugu, halere, aukera galdu nahi izan «Iracurtçailleari» zuzendutako hitzaurrearen «etorkiaren iturburu» izan zitekeen pasarte bakanen baten berri ere emateko³ ; hipotesi gisara, esan nahi baita.

Sobran legoke, ziurrenik, urdazubiarraren jokamolde eklektikoaz han eta hemen azpimarratu dena eta geuk ere sarritan mahairatu izan duguna errepikatzeari ekitea. Hark irakurleari luzatutako gutuna, argi da, tankera horretakoa da, eta ez iturbegi

1 Aurrera dezagun liburua osatzen duten zortzi diskurtsoetako lehen biak baino ez zituela Axularrek erabili lehen kapitulua bideratzeko.

2 Ohargarria da nola erabili izan den liburu honen erreferentzia berdin nagitasunaren aurka jotzeko (ikus González Ramírez, 2010) nola, beranduago -gure Lafarguek ikusi izan balu!-, soldatapeko lanaren apologia egiteko.

3 Ikus artikulu honen amaierako Eranskinean Guzman-en «Al Christiano lector» (1614, qq3-ifrentzua) delakotik ateratako pasarteak. 
bakar bateko urez zipriztindua. Baina bestelakoetatik xurgatutakorik islatu arren (ikus Salaberri, 2000), orain arte kaleratutakoa osatu besterik ez luke egin nahi gaurkoan dakargun ataltxoak, eta ez delako iturri-aniztasun hori osoki zehaztu.

Eklektizismoaren harian, lehen kapituluko «jolasa» genuke Axularren estiloaren ezaugarriak hobekixeago erakutsi litzakeena, eta, batik bat, jatorrizko testutik jasotako fitxa eta ohar gisakoen antolamendu berriko prozedura argixeago utziko lukeena.

Aitortu behar da, dena den, Axularrek ongi pentsatua, atondua eta zurkaiztua ohi duela kapituluen egitura nagusia hasieratik, eta egitura hori batik bat erlijiozko aipuen gainean sostengatua daramala lehendabizitik. Dotrina-munduko zurkaitz haien arteko eskala argumentatzailea izaten da gero eraikitzen duena.

Hartara, ondoko orrialdeetan istorio eta etsenpluen bidezko osatze, hornitze eta aberaste-lana ohi du ageriko. Intentsitate handiagokoa batzuetan -gainerako ataletakoa baino gehiagokoa da lehen kapitulukoa, adibidez-, baina betiere garatu nahi denaren mailako janzte egokia. Axular bezalako idazleen jokamolde erretoriko landuaren erakusgarria, azken batean.

\section{BOSGARRENA}

Baina ikus dezagun astiroago lehen kapitulu horren zurkaizte eta ehuntze-lana.

Aspaldi hartu genuen Terrones del Caño Axularren garaiko erretorika eklesiastikoaren joera praktikoaren aholku- eta argi-emaile gisara eta, beste zurrunagorik ezean, haren Instrucción de Predicadores liburua baliatuko dugu oraingoan ere urdazubiarrak Geron egiten duenera hurbiltzeko eta, ahal den heinean bederen, ulertzeko iparrorratz modura 4 .

Esana da jadanik (Salaberri, 1997), eta ez dugu iltze berean berriz mailukatuko, Axularren testuen egituraketaren azpian ezin agerikoago dautzala predikaziorako eskema orokorrak. Eta zeharo zilegizko ez badirudi ere, horrelakotzat, hots, sermoitzat hartuko dugu aztertzera goazen lehen kapitulua ere.

Terronesen arabera, sermoiak honako parte hauek izan behar ditu, oro har: «exordio, narración, confirmación y epílogo» (Terrones, 1617/1960, 100. orr.).

4 Ez dirudi Axularrek Terrones del Caño ezagutzeko betarik izan zuenik. Halere, urdazubiarraren jokamolde erretorikoa ulertzeko erreferentzia aproposa aurkitzen da haren liburuan, zeren eta -barka bekigu geure hitzetara jotzea- "Axularren ikaskide izan ez bazen ere, zinez baiezta daiteke tradizio beretik edanak zirela biak, bai Torresek eta bai Axularrek, biek ikasi baitzuten -batak lehenago, geroago besteak- Salamankako ikasgeletan» (Salaberri, 2016, 48. orr.). 
Hona, banaka zehazturik, predikariak atal bakoitzean egin behar omen duena:

a) Exordioa ${ }^{5}$, non gaia latinez («con su libro y capítulo») eta «erromantzez» aurkeztu ondoren, hasi behar baita "por un dicho de un santo [...] o una autoridad de la Escritura, y sacar della algún discursito breve, con que se proponga la materia que se ha de tratar» (101. orr.).

b) Narrazioa, laburra eta argia hasieran, "para que sin rodeos ni metáforas, entienda el auditorio qué materia se ha de tratar» (101. orr.), eta luzeago eta urrunetik hartua zertxobait beranduago, «tomado lo más lejos que se pudiere de la materia que se ha de tratar; cuanto más lejos, tanto mejor» (101. orr.).

Atal bi horiek osatzen duten sarrera orokor horretan predikariak

ha de ir enriqueciendo el discurso por buenas razones, autoridades y ejemplos dulces, para engolosinar y aficionar al auditorio [...] hasta que venga el concluirse y aplicarse a la materia o tema que se propuso, de manera que parezca que vino a encarar con el tema todo el discurso, y que dél se siguió naturalmente el tema o materia (101. orr.).

d) Berrespenaren atalean, aldiz,

se han de ir tratando los miembros de la materia o tema propuesto, por el método de doctrina, primero lo más general y después sus partes [...] Y en cada miembro o proposición que se asienta, ha de venir luego su confirmación con lugares de Escritura, comparaciones, buenas razones u otra variedades [...] que fuere a propósito (101. orr.).

\section{Esanguratsua eransten den gaztigua:}

advirtiendo [...] que para una cosa se han de traer muchos argumentos o pruebas, primero se digan los más eficaces [...] y luego díganse los demás, guardando siempre para la postre un argumento fortísimo o cosa muy sabrosa, porque quede el auditorio, como echado el sello o la apretadera, convencido y satisfecho (101. orr.).

e) Azkenik, behin gezurtatzea burutu ondoren ${ }^{6}$, sermoiaren amaiera dakarren epilogoa letorke, "suma o epítome» delakoarekin hasi beharko litzatekeena, eta non ez baita esandako guztia berriro errepikatu behar,

sino tocar y señalar por algún orden los argumentos más eficaces y los puntos que le pareciere al predicador [...] y aun éstos no se han de repetir por el orden que se

5 Ez ditugu hona ekarriko sermoia predikatzean formalki egin ohi zirenak: hasierako agurra, aitaren egitearena, agurmariaren baten tartekatzea, etab.

6 «La confutación, que es [...] donde se responde a las objeciones que probablemente se podrían poner contra lo que queda probado» (Terrones, 1617/1960, 102. orr.). 
dijeron, sino como mejor vinieren, para un discurso apretado y breve, que se ha de hacer en el epílogo, en orde a meter en el alma del oyente lo que principalmente se pretendió en el sermón (103. orr.).

Balegoke, halaber, zaindu beharreko azken puntu bat epilogoaren amaieran, hots,

la amplificación o exageración de lo que queda dicho y probado hase de hacer con palabras más fuertes, más significativas y aun hiperbólicas [...], con algunos apóstrofes, interrogaciones, exclamaciones sobre lo dicho y probado en el sermón (103. orr.).

\section{SEIGARRENA}

Axularrek, lehen begiratuan atzematen denez, aski era estuan betetzen ditu ezezagun zuen Terrones garaikidearen gomendioak ${ }^{7}$.

Ondo ikusten da hori Geroren hasiera izango den kapituluan bertan. Buru-buruan, esaterako, eta "gomendioek» aholkatu bezala, Bibliaren lehen liburuarekin irekitzen du diskurtsoa; areago -eta ederrago-, gizakiaren sortzearekin berarekin -eta horrek dakarkion sinbolismo guztiarekin- ekiten dio gaia aurkezteari. Eta horretan ari dela, lehen liburuko bigarren bertseta hautatuz mahaigaineratuko du obra guztiaren ardatza izango den muinera iristeko latinezko esaldi prezeptiboa.

Denbora falta zaio Terronesek aholkatu urratsa betetzeko, jarraian planteatzen baititu, Patrologiak arlo latindarrean zein greziarrean dituen teologo-hermeneuta handienen hitzekin, Gerorako hautatu gaia garatzeko interesgarrien zitzaizkion interpretazioak.

Ezin ziur jakin nondik jaso zituen Axularrek san Tomasen eta san Krisostomoren pasarteak ${ }^{8}$, baina, guztiarekin, eta Akinoko doktorearen autoritatea gaitzetsi gabe izan bazen ere, Urrezko Mibidunak eskainitako beste arrazoi bat lehenetsi zuen urdazubiarrak, «ni narraikan pontuari hobeki hurbiltzen zaika» eta (1643, 22-23. orr.).

Garatu nahi zuen diskurtsorako ikuspuntua, hortaz, finkaturik utzi zuen Axularrek horrekin. Argumentatzea zegokion segidan, eta zer hobe ideiak exempla zenbaitekin, modu ezin ulergarriagoan eta goxoagoan, garatzea baino? «Ejemplos dulces, para engolosinar y aficionar al auditorio", zioen Terronesek.

7 Ez beti kapitulu guztietan berdin jokatuz, noski, gai batzuk biziago eskatzen eta onartzen baitituzte, adibidez, epilogoko galdera- eta harridura-ikurrak, apostrofeak eta beste.

8 Zail egiten da Akinokoaren Summa osoa izan zezakeela pentsatzea, baina eskura izan zezakeen, halere. Zalantza gehiago legoke Krisostomoren lan zabalaren aurrean, 1718ra bitartean -ordukoa da Montfaucon-ek apailatu edizio osoa- titulu soltetara mugatzen baitzen Antiokiakoaren obra izateko aukera. Gogora bedi orotara hiru dozena aldiz libururatzen duela urdazubiarrak Akinatearen lekukotasuna -esan bezala, ia kasu guztietan Summa erraldoi baina aurkierrazetik jasoa- eta berrogeita hamabost bat bider Krisostomorena, honen aipu gehienak homiletikoak direlarik eta halabeharrez obra eta orrialde-kopuru gehiegiren artetik bilduak. 
Guzmanen liburua harrobi aberatsa da arlo horretan (ikus artikulu honetako Eranskinean aurkezten den testu-konfrontazioa) eta, hortaz, Bibliako pasarteren batekin eta teologoen azalpenekin uztartzen zihoala, harenetik jaso bide zuen gure idazleak lehendabiziko istoriotxoa, san Kasianok kontatutakoa (ik. Guzman, 1614, 32. orr.), gradazio teologiko-diskurtsiboen karietara prezeptiboa-edo baitzen aurrenekoak tradizio erlijiosoko lekukotasunak izatea.

Garrantzizko intzidentzien zerrenda aberaste aldera, azpimarratzekoa da -hartan berresten bide baita, besteak beste, Guzmanen iturriaren erabilera- garraiatu aipu haietako batean Axularrek burutu zuen akatsa (1643, 23-25. orr.). Nonbait, fitxa gisakoetan ondozkaturik zeuzkan gure idazleak berean tartekatu behar zituen pasarteak (Guzman, 1614, hurrenkera honetan: 16-17, 12, 13. orr.), baina san Anbrosioren erreferentzia ematean (iturburuan, «S. Ambros. Sup.» izanik, lerro batzuk gorago zegoen «Praefat. in Lucam» delakoa behar zuena), nahasi egin bide zen urdazubiarra eta, Guzmanenean «Sup.» hari zegokionaren ordez, berak ondutako testuan bertan gorago zeukanetik jaitsi zuen datua. Berean -liburuan 24. orrialdea izango zen hartan-, El Tostado "Abulentsea»-ren «in praefat. in Levit.» zeukan jasoa eta, errakuntzaz ohartu gabe, huraxe erantsi zion Anbrosioren izenari (1643, 25. orr.).

Jentilen -kristau ez zirenen- etsenpluak eta haiengandik ikas daitezkeenak etenketa -muga- diskurtsibo-bisualaren ondoren etorriko dira segidan, izan ere, lehen atalean ( $\$ 1 ; 1643,25$-hk.) hasiko baitira agertzen eta, taxuz eta esajeraziorik gabe bada ere, ugaltzen, betiere xede nagusia argi delarik: jendea alferkeriaren arriskuetatik at uztea eta bekaturako aitzakia omen zen hura desterratzeko baliabideak jartzea.

Nabarmentzekoa da ahalegin errukior horretan Axularrek, Aristoteles eta Plutarko bezalakoen autoritateaz baliatuz ${ }^{9}$, egiten duen argudiatze estentsiboa: jendea lan erraldoietara behartzetik eta lanez zamatzetik, egungo politikan ohiko bezain klasiko bilakatu den aukera miresgarria planteatzeraino, hau da, «erresuma»-tik kanpo gerrak pizteraino doana. Benetako atzerriak eta etsaiak behar dituen aukera honek ernatu egiten du, antza, gizakia eta ez omen dio loakartzen uzten.

Nonbait ahaztu egin zitzaion urdazubiarrari -zegokien garaitik at zeuden-eta orduko euskaldunak ere- munduko hautsak harrotzen ibiltzen direnek nahiago izaten duten beste abantaila bat ere aipatzea: erresuma barneko erresuminak, ezinikusiak eta etsaigoak ahaztu egiten direla kanpoko etsai larriaren aurrean, eta, aldi berean, trinkotuago eta bateratuago gertatzen dela erresuma barnekoen arteko fraternité

9 Interesgarria Guzmanenean $(1614,15$. orr.) Aristotelesen ondoan datorren Plinioren lekukotasunarekin egiten duena: haren hitzak euskaratu arren («cuya fabrica dize tambien Plinio se començo, para que el pueblo no estuviesse ocioso [Ne plebs esset otiosa]» > «zein eragin baitzituen errege Faraonek, iendeak alfer etzeudezin amoreakgatik»), testua aipuz beteegi edo ez uztearren -beherago ez baitu Plinioren izena aipatzeko eragozpenik [ikus 1643, 35. orr.]-, Axularrek ez du inolako erreferentziarik ematen (1643, 25-26. orr.). Eta berdintsu jokatuko du aurrerago ere $(1643,31$. orr.). 
delakoa eta, agintari moderno horietakoren batek esango lukeen moduan, biziki areagotuago identitatea eta pertenentzia-sena.

Baina ez, Axularrek ez zion probetxu politiko hori ikusi kanpoko etsaiak izateari, Guzmanen «plutarko»-ren ildoan eta kristau zintzo gisara, probetxu handien eta printzipalen iritzi baitzien alferren trabailarazteari, lotien iratzartzeari eta ezantsiatuen adoretzeari. Erlijiozko sinesmena gailen, bada.

Eta berriro ere, etsaien probetxuaren aldeko jarrera horretan san Krisostomoren lekukotasuna baliatuko du jarraian, berau ere nondik atera zuen -haren obratik zuzenean, agian?- ziur ez dakigula.

Nolanahi den, Guzmanek erantsitako ideia bat hanpatuz ixten du gure idazleak atala (1614, 62. orr.).

Bigarren atala $(\$ 2 ; 1643,29-\mathrm{hk}$.) bete-betean eskaintzen zaie istorio eta lekukotasun historiko laiko-profanoei, batzuk, gehienak, Guzmanen obratik jasoak bide direnak; bakanen bat, Periklesena eta korintiarrena hain preseski, jatorrizkotik hartuak ez diruditenak.

Duen bitxitasun-ukituagatik nabarmendu nahi genuke korintiarrek alferrekiko zuten portaeraren amaieran Axularrek egiten duen iruzkin propioa, idatzizko diskurtsoetan aholkatua izaten ez dena, bidenabar esateko. Antza denez, ez zaio irakurle eskarmentatuaren konbertsiorako aski iruditzen adibidea bera ekartzea eta ezinbestekotzat jotzen du korintiarren garaian egiten zuten hura berrestea eta bere garaikide alferrekin berdin jokatzeko proposamena egitea. Eta proposamena -horratx Axularren espiritu urrikalkorra- ez da edonolakoa: alferrak hiltzea (ederragoa da haren eufemismoa: haiei «bizia edekitzea») aldarrikatzen du gure idazleak ezer esaten ez duela dirudien lerroska labur hartan: "on lizate orai ere, halakoekin hala egin baledi» (1643, 32. orr.).

Horren aurrean, pentsatzekoa da zer ez ote zuen proposatuko hogeita hamar urte lehenago Sarako «sorgin» omen ziren haien aurka -hau da, frantziar monarkiaren eta sinesmen kontrarreformistaren alde-, bera bertako erretore edo apaiz nagusia zenean ${ }^{10}$.

Oldozpenak oldozpen, Guzmanen liburutik ateratako beste istorio eredugarri gehiagorekin segituko du alfer madarikatuen aurkako diskurtsoa, tartean iturburu identifikatu gabeko besteren bat dagoelarik.

Guztien ondoren, eta aipuen ohiko gradazio tridentinoari uko egin gabe (ikus Salaberri, 1998, 233-hk.), filosofoen zalantza eta borondate oneko iritzi okerrei irekitzen zaie tarte bat diskurtsoaren tesia -hots, «alferqueria» eta «alfertasuna gauça gaixtoa, 
perilosa eta norc bere ganik egotztecoa cela» $(1643,34$. orr.) zioena- teorikoki ere berretsi ahal izateko.

Eta argudioari tiratuz, zehaztu egin nahi izango da zergatik ez den alferkeriatan aritu behar, izan ere, gizakiak, izaki guztiek, esentziaz baitira zerbaitetarako sortuak, eginkizun garbi eta zehatz bat betetzeko eginak nonbait, hegaztiak hegan egiteko bezala, gizakiak lan egiteko, trabailatzeko jaioak.

Oraintsu adierazi bezala, garrantzi berezia du argudio-gradazioaren gaiak esku artean darabilgun diskurtsoan, eta ondoren datorrenak egoki islatzen du noraino zuen Axularrek bereganatua aipatu mailakatze estu horren betebeharra, agerikoa baita artean ez diola leihorik zabaldu nahi izan «munduko gauzen» lekukotasunari. Alabaina, dela gauza, dela animalia, azken orrialdeetan agertuko du haiek ere alferraren eta alferkeriaren aurka daudela, aurkako sen hori berezko balute bezala erakutsiz.

Eguzkiaren lekukotasuna lehendabizi, zuhaitzena gero, irudi garrantzizkoenak eta eredugarrienak, halere, gizakiarenak bezalatsuko ezaugarriak dituzten bizidunen agertzetik etorriko dira berehala. Tradizio kristau zabalean gogokoen diren zomorroak, bada, protagonista. Azken lerroak inurriei eta erleei eskainiak dira, beraz, nonbait haietxek beharko baikenituzke gizakiok ere bizimodu-eredu.

\section{AZKENTZA}

Hona ekarri gaituzten puntu bietara itzulirik, eta labur-zurrean bada ere, begi-bistakoa da lehen kapituluaren ehuntze-eskema horretan egokiro begiratu zuela Axularrek Terronesek gomendatzen zuen diskurtso-egituraketa, eta, eginkizun hartan zegoelarik, ongixko baliatu zuela Guzmanen liburutik xurgatutakoa ere. Horrela jokatuz, jakina, ezin hobeto erakutsi zuen nolako erraztasunaz irentsi eta digeri zezakeen besterena zena eta noraino egin zezakeen guztiz bere handik eta hemendik garraiatutakoa. Axularren trebetasunak erantsi zion edertasunaren plusa gutxietsi gabe, erretorika eklesiastikoak aholkatzen eta bilatzen zuena baino ez, beraz.

Uste izatekoa ere da -honatx artikuluaren azken korolarioa- Gerok dituen kapitulu gehienetan jokatu zuela berdin antzean gure idazleak. Baina, tamalez, gupidagabeki burututako ehiztaritza egoskorrak baizik ez lezake altxor hori guztia deskubri.

Aramaion, 2017ko ekainaren 13an 


\section{ERANSKINA}

\section{GERO}

\section{OHARRA}

Ondoren ikus daitekeen legez, Gerotik jasota erantsi den kapitulua, oso-osorik, ezkerraldeko zutabean kokatua dago ${ }^{11}$.

Bestalde, antzak, kidetasunak eta ustezko iturburuak identifikatzeko kontraste eta erreferentzia nagusi gisa, Pedro de Guzmanen Bienes de el honesto trabajo y daños de la ociosidad en ocho discursos (Madril, 1614) izeneko obra baliatu dugu ${ }^{12}$. Handik garraiatuak diruditen pasarteak dira Axularren testuaren parean txertatu direnak ${ }^{13}$.

\section{IRAKURTZAILLEARI}

Egun batez, konpaiñia on batean, euskaldunik baizen etzen lekhuan nengoela, ekharri zuen solhasak, izan zen perpausa, etzuela, deusek ere hanbat kalte egiten arimako, eta ez gorputzeko ere, nola egitekoen geroko utzteak, egunetik egunera, biharretik biharrera luzatzeak [...] Eta hala deliberatu nuen [...] liburutto baten, bi partetan partiturik, gero hunen gaiñean egitera (Axular, 15-16. orr.).

Baiña ikhusirik zein gauza guti edireiten den euskaraz eskiribaturik, gogan behartu naiz eta beldurtu, etziren bideak asko segur eta garbi, baden bitartean zenbait trabu edo behaztopaharri. Eta halatan hartu dut gogo, lehenbiziko parte hunen, lehenik benturatzeko, eta berri iakitera bezala aitzinerat igortzeko. Hunek

\section{AL CHRISTIANO LECTOR}

Por no esta ocioso unos dias [...], en un lugar [...] tomé la pluma para escrivir contra el ocio, descubriendo todos los principios, efectos, y circunstancias del. Y determineme a ello en una conversacion con una persona [...], en que tratamos de los muchos daños que la ociosidad hace [...] (Guzman, qq3).

He me holgado se aya ofrecido esta occasion, de embiar delante este breve tratado, para que sirva como de explorador, ò espia, quiça perdida, y vea si està seguro el campo, en que militan las lenguas, y me trayga nuevas del gusto, que ay desta manera de escrivir [...] Conforme a la relacion, y nuevas que me

11 Axularren testuen honetaratzeko Armiarmak eskaini bertsioa erabili da, hots, http://klasikoak.armiarma. eus/idazlanak/A/AxularGero.htm

12 Maiz asko eztabaidatu izan bada ere iturburuen bila aritzeak dituen zailtasunez, oharño bat erantsi nahi genuke Axularren iturri hau dela eta. Izan ere, alferkeriaren gaia jorratu duten autore kontrarreformista askok ikuspegi eta trataera berdintsuak erakutsi dituzte eskuarki, eta areago, ekarri ohi dituzten adibideak, istorioak eta aipuak berak ere berdin-berdinak suertatzen dira kasu askotan. Horrek, esan beharrik ez da, biziki gaizten du eginkizuna.

13 Kapituluaren osaketaz jabetze aldera, bilduma barnean sartu da Torresenetik jasotakoren bat ere (ikus Salaberri, 2016). Guztiarekin ere, ez da hemen aintzat hartu silva edo locietatik bildua izan zitekeen aipurik, erabiliegiak suertatu baitira deboziozko liburu guztietan inoren iturri zuzentzat hartu ahal izateko. 
zer iragaiten den, zer begitarte izaiten duen, eta nor nola mintzo den, abisu eman diazadan. Gero abisu haren arauaz ethorkizunerat gobernatzeko: eta bigarren partearen kanporat atheratzeko, edo barrenean gelditzeko eta estaltzeko (Axular, 16. orr.). truxere, saldra à luz, ò no, otro mayor esquadron de algunos trabajos mios [...] que aora estan como en celada, aguardando lo que he dicho (Guzman, qq3).

Embio al Christiano Lector la muestra del paño: con toda libertad puede dezir lo que le parece para que yo ò desembuelva, y corte esta tela, ò la guarde recogida y escuse el sacarla a luz (Guzman, qq3 ifrentzua).

No queria el Señor al hombre ocioso, assi para darle ocupacion contra el ocio, le entregò el jardin del Parayso; para que le labrasse y guardasse (Ut operaretur, et custodiret illum. Gen. 2. num. 15.) ${ }^{14}$ (Guzman, 5. orr.). u, dohain, eta abantail suertez dotaturi egin zuenean, ibeni zuen berehala, lurrak zuen parterik, eta aurkientzarik hoberenean, lurreko parabisuan, lekhu plazerez bethean. Eta manatu zuen lant zezala, labora zezala, eta begira ongi parabisu hura: Posuit eum in paradiso voluptatis, ut operaretur, et custodiret illum (Gen. 2) (Axular, 21-22. orr.).

Ordea nola lur-lantzea, aphaintzea, laboratzea, eta begiratzeko beharrean eta premian ere iartzea, bekhatutik sortzen eta heldu diren xertoak, landareak, fruituak, eta ondoreak baitira, eta oraino orduan ezpaitzen bekhaturik, eta ez bekhaturen aierurik, omenik eta ez aiphamenik ere, badirudi ezen etzela halaber, oraiño orduan, parabisu haren lantzeko, eta begiratzeko premiarik.

Zertako, beraz, eman zioen orduan, Iainkoak gizonari, manamendu hura? Ihardesten du San Tomasek, erraiten duela: Nec tamen, illa operatio esset laboriosa sicut post peccatum, sed fuisset jucunda, propter experimentum virtutis naturae. Custodia etiam
14 Euskarazkoan bezalatsu, gaztelaniazko testuan alboan doazen aipuak eta erreferentziak ere hemen testuaren barnean emango dira parentesi artean. 
illa non fuisset contra invasorem, sed esset ad hoc, quod homo sibi paradisum custodiret ne ipsum amitteret peccando (S. Thom. 1. p. qu 102 art. 3). Etzen ez orduko trabaillatze hura, penagarri izanen, orai bekhatu eginez gero bezala. Baiña hura izanen zen atsegin hartze bat, eta bere plazerera, eta aisiara zegoela, bere indarraren eta anzearen frogatze bat. Eta begiratzea ere, ez etsaietarik, baiña bereganik, eta beretzat bekhatuz galtzetik begiratzea, izanen zen. Hunela dio San Tomasek.

Baiña San Krisostomok emaiten du bertze arrazoin bat, ni narraikan pontuari hobeki hurbiltzen zaikana, erraiten duela: Propterea praecepit Deus ut operaretur illum, si enim laboris omnis fuisset expers, ex nimio otio, in ignaviam fuisset prolapsus (Chrys. hom. 14 in cap. 2 Genes. tom. 3). Egia da, etzen oraiño orduan, lur-parabisu hartan egitekorik, etzen trabaillatzeko premiarik. Ordea halarik ere, etzuen nahi Iainkoak, han zegoena, zegoen geldirik: ez trabaillatzetik alfertzera, eta nagitzera ethor etzedin, eta zein gauza gaixtoa zen, eta den alferkeria, aditzera emaiteagatik (Axular, 22-23. orr.).

Kontatzen du Kasianok, Paulo abade zahar hura, palma adar batzuk harturik, hetzaz, zare, saski eta otharre egiten haritzen zela eta gero azkenean, egin ondoan, astearen buruan, guztiak erratzen eta desegiten zituela (Casian. lib. 18 cap. 14). Zeren bataz, nola herrietarik urrun baitzegoen, gehiago baitzekarkeien garraioaren gastuak, obraren balioak baiño: eta berriz bertzea, zeren trabaillu hura guztia orazinotan eta othoitzetan unhatu ondoan, alferkeriatik ihes egiteagatik, hartzen baitzuen, eta ez ondoko irabaziagatik.

Gure Iaungoikoak eman zituen lege zaharrean seietan ehun eta gehiago manamendu eta zirimonia suerte, eta hekin batean hanbat egiteko, non erraiten baitu Iondone Petrik, ez berak, eta ez haren aitzinekoek ere, ezin bururik egin zutela, eta ez iasan hain karga handia. Quod neque patres nostri, neque nos portare
Dize [...] Casiano del Abad Paulo, santissimo viejo, que trabajava todo el año, haziendo obras de palma, y al cabo del las quemava, porque este trabajo solo le tomava, por huyr de la ociosidad (Casia. li. 10. cap. 24) (Guzman, 32. orr.).

Preguntan algunos, por que el Señor cargò de tantas ceremonias y ritos, y de tanto genero de sacrificios à este mismo pueblo, obligandole con un numero innumerable de preceptos, que llegavan à seyscientos y treze [...] que bastavan a quebrantarlos los mismos huessos, parte de la intolerable carga, que encarece el Apostol S. 
potuimus. (Act. 15). Eta nahi baduzue iakin ea zergatik kargatu zituen Iainkoak hanbat manamenduz, ihardesten du doktor batek: Ut per operationes variorum sacrificiorum otiositas tolleretur, quae multis malis initium tribuit et fomentum (Abulen. in praefat. in Levit). Kargatu zituen hanbat manamenduz, sakrifizioz eta zirimonia suertez, hekin batean khen zedin, hanbat kalteren eta damuren haste eta pitzgarri den alfertasuna.

Nola gure Iaungoikoak beztitu baitzituen lurreko animaliak, aireko hegaztinak, itsasoko arraiñak, eta oihaneko zuhaitzak ere, bere beztimenda suerte batzuez. Animaliak larruz eta illez: hegaztinak lumaz: arraiñak ezkataz: eta zuhaitzak azalez. Eta nola zuhaitzak bere dauden lekhuetarik higitu gabe, eta trabaillatu ere gabe, bere azpiko lurraren gozoa eta gizentasuna, beregana, bere erroez thiratuz eta edoskiz, hazten, handitzen eta mantenatzen baitira: animaliek ere bere bazkak eta iatekoak, berehala, eho gabe, erre eta egosi gabe, iaten baitituzte: eta bai bere etxeak eta etzauntzak ere, non nahi den, arratsten eta ilhuntzen zaien lekhuan hartzen: eta gehienak, berehala bere ameen ondotik baitoazi; zein baitira abantail handiak. Hala Iainkoak nahi izan balu, eman zerauzkaion gizonari ere abantail suerte hauk guztiok, eta gehiago ere. Beztitu zukeien, etxedun egin zukeien eta deus gosta gabe, behar zuen guztiarekin ibeni zukeien. Ordea etzuen hala ibeni nahi izatu. Eta zergatik ez? Alfer etzegoen amoreakgatik. Eta San Anbrosiok dioen bezala, errezibitu duen adimendua enplega dezangatik. Soli autem homini, ut rationale quod accepit exerceat, vitae cursus in labore praescribitur (Ambros. in praefat. in Levit) (Axular, 23-25. orr.).

Zeren baldin orai, gauza guztiak hain nekez eta hanbat gostarik, erdiesten ditugularik, hain nagi eta alfer bagara; zer geneidike, nahi dugun guztia, nahi bezala eskuen artean bagendu? Deus falta ezpalitzaiku? Erran genezake Ebanjelioko aberats hark bezala: Anima,
Pedro [...]. Responde el doctissimo Abulense: Para que on la ocupacion de tan varios sacrificios y ceremonias se quitasse la ociosidad, que es principio y fomento de muchos males (Ut per occupationes variorum sacrificiorum, \& caeremonialium observationum otiositas tolleretur, quae multis malis initium tribuit et fomentum (Abulens. in praefat. in Levit). (Guzman, 16-17. orr.).

Bien pudiera el Señor, como vistio à los animales de la tierra, y a los peces del mar, y à las aves del ayre de libreas diferentes, à unos de lasa y pelos, à otros de duros cueros, à otros de plumas, à otros de escamas, y à los arboles de cortezas (11 or.): y como un durissimo roble se sustenta, estandose en un lugar arraygado en la tierra, chupando con las bocas de sus rayzes el delicado humor jugo della: y como los animales se sustentan, ò de las yerbas y rayzes que inmediatamente arrancan de la tierra, sin mas prepararlas, ò disponerlas, ò del duro, y entero grano que hallan, sin molerle, ni partirle [...]: y como todos los animales hallan en la tierra formadas sus cuevas, y agujeros donde se alverguen y guarecen [...], aver traçado que el hombre se vistiesse y sustentasse, y habitasse sin tanta costa ni trabajo. (Guzman, 12)

A los demas animales -dize S. Ambrosio [...]- la tierra -por mandado de Dios- les produze el fruto, à solo el hombre, para que exercite la parte racional que recibio, se le manda gastte la vida en trabajar (Soli autem homini, ut rationabile, quod accepit vitae cursus in labore praescribitur. S. Ambros. Sup. [Praefat. in Lucana]), para sustentarse, $y$ assi se verifique [...]. (Guzman, 13. orr.). 
habes multa bona, posita in annos plurimos, requiesce, comede, bibe, epulare (Lc. 12). Dezagun ian eta edan; dezagun pausa eta atsegin har; zeren berdin eztugu deusen eskasik, eztugu egun hautan eskean ibiltzeko perilik (Axular, 25. orr.).

\section{$\mathbb{1} 1$}

Erraiten du Aristotelek on dela, alferkeriaren herritik khentzeko eta desterratzeko, eta herrien ere bere erregeren edo bertzeren kontra iaikitzetik begiratzeko, zenbait obra handiren hastea, zenbait dorreren edo gazteluren egitea, eta hetan iendearen enplegatzea (Arist. lib. 5 Politic. cap. 11). Nola ageri baita Ejiptoko Piramidetan, zein eragin baitzituen errege Faraonek, iendeak alfer etzeudezin amoreakgatik. Iduriturik errege hari, ezen baldin Israeleko seme gathibu bezala bere azpian zedutzan hek (iragaiten baitziren seietan ehun milla presunatan) utzten bazituen bere plazerera eta aisiara bizitzera, urguillutzeko eta nabusitzeko bidean iarriko zirela, eta handik behar etzena sorthuko zela, egin zuen Piramide batzuen egiteko gogoeta, asmua eta pensua. Eta Piramide hetzaz mintzo dela, erraiten du San Isidorok: Pyramides est genus sepulchrorum quadratum fastigiatum ultra omnem celsitudinem, ut a lato incipiant et in angusto finiantur (Isidor. lib. 5 Ethimol. cap. 11). Piramidea edo Piramideak ziren sepultura suerte batzuk, pilare, harroin, edo thonba laur kantoinetako gora ailtxatu batzuk, egin ahal zitezkeien gorenak, ondoan zabal eta puntan mehar. Eta hetan trabailla arazitzen zituen Faraonek bere azpiko iende hek, seiñalaturik bat bederari, bere eguneko lana eta sailla. Eta eskuaren ibentzea bera asko bazuketen ere, ordea lanhabesak, tresnak, eta obraren egiteko gai guztiak ere, berèk bilhatu eta hornitu behar zituzten. Eta halarik ere, ezin ausart zitezkeien arrenkuratzera: halako moldez ezen hartako lehenbiziko hitza ahotik itzuri zeienean, erran baitzerauen berehala Faraonek:
Dize Aristoteles, que para desterrar el ocio de la Republica, y ocupar a los ciudadanos, de manera que no tengan lugar de rebelarse, ni tratar entre si desto, es bien començar grandes y sobervios edificios. Testigos son desto -dize- las Pyramides de Egipto (Huius rei exemplo sunt Pyramides Aegypti. Lib. 5. Polyt. c. 11.), cuya fabrica dize tambien Plinio se començo, para que el pueblo no estuviesse ocioso (Ne plebs esset otiosa. lib. 36. cap. 12.). Fue el caso, que temiendo el Rey Faraon que los hijos de Israel, que se avian multiplicado en grandissimo numero (Iosephus [...]), podrian tratar entre si levantarse con el Reyno, ò yrse del, de quienes se servia como de esclavos, dio traça en ocuparlos à todos que eran mas de seyscientas mil personas (Vide Isidorum lib. 15. Ethy. cap. 11) [...] Y quejandose ellos de la grave imposicion y tarea de los ladrillos que avian de hazer, sin quererles dar todos los materiales necessarios para ellos, les respondio el Rey: Estays ociosos (Vacatis otio. Exod. 5. num. 17.), y quejays os de vicio? Pues yo os cargarè de mas, para que no lo esteys (Guzman, 15-16. orr.). 
Vacatis otio (Exod. 5). Asti duzue, zeuen ongiegiak, alferkeriak, aisetasunak iratxekitzen deratzue, hark horrela kilikatzen eta mintza arazitzen zaituztezate. Eta halatan aitzinerat kargatuago zituen, lana berretu zerauen. Eta hura guztia egiten zuen, baldin bat ere astirik bazuten, edo alfer bazeuden, handik zerbait ethor zekion gogan beharrez eta beldurrez (Axular, 25-26. orr.).

Pisistrato Atenasko tirano gaixto hark ikhusi zuenean plaza guztia iende alferrez bethea, eta hetarik anhitz malizia eta pensu gaixto sor zitekeiela, deitu zituen guztiak beregana. Eta aitzinerat alfer egoiteko desenkusarik etzutentzat, eman zerauen mando, zamari, idi, hazi, diru, finean trabaillatzeko behar zuten guztia. Eta gero igorri zituen lanera eta trabaillura, iduriturik ezen halatan etzutela kalterik eginen, maliziarik pensatuko, eta ez herririk nahasiko. (Aelianus, lib. 5 variis histor.) (Axular, 27. orr.).

Munduko berri dakitenek erran dute eta erraiten dute, on dela herrientzat eta erresumentzat, zenbait egiteko eta gerla bere herritik eta erresumatik kanpoan izaitea. Zeren nola bat bedera bakearekin lohakartzen, ez-ansiatzen eta gorputzaren plazeretara emaiten baita. Hala gerlèkin, etsaiekin eta kontrastekin ernatzen, iratzartzen, eta axolduritzen da (Axular, 27. orr.).

Plutarkok egiten du liburu bat, etsaietarik atheratzen den probetxuaz, eta guztiètako handiena eta prinzipalena dio dela, alferren trabailla arazitzea, lotien iratzartzea, eta antsikabèn ansiatu eta arduratsu egitea (Plutarc. lib. de utilitate ex inimicis capienda). Adiskidèn artean garenean laxo gara, eztadukagu deusez ere konturik: eztugu gaizki mintzatuagatik eta milla erhokeria eginagatik ere antsiarik. Zeren baitakigu, ezen adiskide direnaz geroz, hek guztiak estaliko eta
De la mesma industria uso Pisistrato, el qual en tomando posesion del reyno, luego puso los ojos en atajar platicas de hombres valdios, porque de otra manera, no se tenia por seguro en aquel estado: para esto se salia a la plaça, y en viendo algunos pasearse de valde, los llamava, y [...] asi a uno dezia: si no tienes bueyes para labrar la tierra, ve y toma de los mios, y trabaja para comer: a otro dezia: si te falta trigo para sembrar [...] toma lo que quisieres, y no vivas tan holgazan: todo lo qual hazia, dize Eliano: Veritas en horum ocium insidias aliquas pareret (Aelian. De varia hist. 1i. 9) (Torres, 793-794. orr.).

Hizo un libro Plutarco, que intitulò, de utilitate ex inimicis capienda, de la utilidad que se ha de sacar de los enemigos, y la principal es de ociosos, y descuydados hazer cuydadoso, y recatados (Guzman, 61. orr). 
onera hartuko derauzkigutela. Baiña etsaien artean garenean, behar dira buru-beharriak ernatu, zer egiten eta erraiten den behatu. Zeren nola etsaiak bethiere zelatan baitaude, zer ere huts edo falta edireiten baitute, hura berehala harrapatzen dute, eta are batzutan berreturik, airatzen eta kanpatzen dute (Axular, 27-28. orr.).

Hargatik erraiten du San Krisostomok: Saepe vero ab inimicis non minus lucramur quam ab amicis. Cum enim nobis peccata exprobraverint, et iam invitos, in ipsorum correctionem excitant (Chrys. hom. 13 ad populum Anthio. tom. 3). Anhitzetan egiten derakute etsaiek hanbat ongi eta ontasun nola adiskideek, eta bai batzutan gehiago ere. Zeren etsaiek geure faltak erranez, eta hetzaz eranzute eginez, emaiten derakute okhasino ernatzeko, iratzartzeko, falta eginen emendatzeko, erremediatzeko eta bai are aitzinerat gehiago egitetik ere begiratzeko (Axular, 28. orr.).

Arrazoin hunengatik erran ahal diteke, etzuela egundaiño, gure Iaungoikoak nahi izatu akhaba zekizten Israeleko seme hei bere etsai guztiak, baiña ordenatu zuen, edo permititu, geldi zekien bethiere zenbait bakhotx eta hondar iratzartzeko, ernatzeko, eta alfertzetik begiratzeko (Axular, 28-29. orr.).

\section{$\mathbb{2} 2$}

Irabazi zutenean Lazedemoniakoek bere fronterako hiri etsai bat, mugakide zuten bat, erran zuten Lazedemonia hartako bereko gobernariek: Sublata est pubis nostrae palaestra, non habebunt post hac, quibuscum luctentur adversarios (Plutarc. in Aphothe). Egin da gure iende gazteaz, eztute hemendik aitzina ihardukitzeko paradarik izanen eta ez borrokatzeko etsairik.

Lazedemoniako hek berèk etzuten desegin nahi izatu hiri kontrast bat, bethiere bere kontra eta etsai izan zuten bat, erraiten zutela,
Este mismo consejo, entre otros, tuvo el altisimo Dios, en no querer acabar de destruir del todo aquellos pueblos enemigos, que echaron los de Israel, de la tierra de Promision (Guzman, 62. orr.).

Y el mismo [Plutarko] en sus Aphophtemas cuenta, que aviendo los Lacedemonios ganado una ciudad fronteriza enemiga, dixeron los governadores: Quitado se ha à nuestra juventud el lugar donde exercitarse, y no tendra contrarios con quien luchar (Sublata est pubis nostrae palaestra, non habebunt posthac, quibus cum luctentur adversarios (Plut. In Apo.): y los mismos, no permitieron destruir un pueblo enemigo, llamande la piedra de aguzar de nuestra juventud (Iuventutis nostra cotem. Plutar.), donde se afilan los filos de su valor. 
ezen, hiri hura zela, Iuventutis cotem: gaztetasunaren zorrotz-harria, zeren gaztèk han bere indarra eta antzea frogatzen, zorrotzten, eta herdoiltzetik begiratzen baitzuten. (Plutar. Ibid.).

Hunen arauaz ihardetsi zuen Kleomenes Sparziako hark ere, galdegin zeraukatenean, ea zergatik hala bere meneraz gero, etzituen bere etsai Argiboak desegin? Ut habeamus qui iuventutem nostram exerceant (Plutarc. in Laco.). Eztitut desegin, dugun amorerakgatik nork gure iende gaztea zertako den froga dezan.

Enzun zuenean Publio Nasikak, egotzi zutela Erromakoek herritik Anibal bere etsai handi hura, Kartago ere hartu zutela, eta hainbertzez, bere ustez, aitzinerat segurean iarri zirela, erran zuen: Atqui nunc in lubrico sumus (Plutarc. in Aphothe.). Aitzitik orai gaude egundaiño baiño linburtzeko eta erortzeko peril handiagoan. Zeren ezpaitugu orai, lehen bezala, iratzartzaillerik eta geure eginbidearen eragillerik (Axular, 29-30. orr.).

Izan zutenean Erromatarrek, desiratzen zuten abantailla eta garaitia Kartagotarren gaiñean, sarthu ziren konseilluan Erromatarrak, ea zer eginen zuten Kartagoko hiri hartzaz (Vide August. lib. de civitate Dei cap. 30 tom. 5). Eta Katonek (prinzipalenetarik bat baitzen) erran zuen guztiak desegin, plaundu eta lurrarekin berdindu behar zuela, zeren bere gerla guztiak eta egitekoak hiri hartarik sortzen zeiztela, eta hura deseginez gero, bakean eta soseguan iarriko zirela. Baiña Szipion kapitain famatu hark ethorkizunari hobeki behaturik, erran zuen: etzutela neholatan ere hiria desegin behar. Zeren baldin desegiten bazuten, gerla bat iraungi ustean, bertze handiago bat pitztuko zutela. Zeren berehala iendea, alferkeriari, ian-edanari, erran-merranei, eta aisiak dekhazkeien gaixtakeria suerte guztiei emanen zeiela. Eta handik nahastekak, diferentziak, guduak, hauziak, etsaigoak, eta Kartagotarrekikoa baiño gerla perilosagoa, bere
Y Cleomenes Espartano, preguntado: porque no avia acabado de destuir à los Argivos? Para que tengamos -dixo-quien exercite à nuestros mancebos (Ut habeamus qui iuventutem nostram exerceant. Plutarc. in Lacon.) (Guzman, 61-62. orr.).

Echado de Italia aquel terror, y espanto de Roma Anibal, y rendida Cartago, alegrandose toda Roma [...] P. Nasica [...] oyendo dezir, que ya las cosas Romanas estavan seguras; Antes aora -dixo- estamos en mas peligro, y mayor contingencia de perdernos (At qui nunc, inquit, in lubrico sumus (Eras. Lib. 6. Apoph.), porque no nos queda quien nos haga estar alerta, y la barba sobre el ombro (Guzman, 62-63. orr.).

Gran contienda hubo en el Senado [...] sobre si convenia assolar del todo a Carthago competidora de su potencia o no (S. Aug. li. .1 de civit. c. 30 ), el voto de Porcio Caton [...] era que se echase de una vez este negocio a una parte, pareciendole que era cosa insuffrible andar toda la vida con el sobresalto de la guerra, y oyendo nuevas temerosas de sus enemigos. Lo contrario defendia Scipion Nasica, juzgando por mas conveniete traer una guerra lenta que sierviese de exercicio y ocupacion al pueblo (Lucius Flor. lib. 2. cap. 15), que no concluyr de una vez con todo, pues se devia presumir, que en faltando quien los truxesse alertos y pensativos de las armas, luego se destruyrian con vicios y regalos [...] pero al fin prevalecio, escribe Plinio (Plin. Nat. Hist. lib. 15. c. 18), el voto de Caton [...] mandaron por decreto publico, que aquella ciudad se arruynasse sin dexar en ella piedra sobre piedra: como lo ordenaron se cumplio, pero como les avia 
arthean sorthuko zeiela. Eta hala gerthatu zen. Zeren Szipionen konseillua utzirik, hartu zuten Katonena, desegin zuten Kartagoko hiria, iarri ziren bere ustez bakean. Baiña Szipionek erran zarauen bezala, fite berak, eta Erromako hiria ere, beheititu eta erori ziren (Axular, 31. orr.).

Baiña Szipionek erran zarauen bezala, fite berak, eta Erromako hiria ere, beheititu eta erori ziren (Axular, 31. orr.).

Egia haur ezaguturik Perikles famatu hark mantenatzen zuen bethiere bere herritik kanpoan zenbait gerla. (Plutarc. in Pericl.). Eta urtheoro igortzen zituen untziak, iendez betherik, gerla hartara. Eta hetan bulkhatzen zituen ediren ahal zitzan alfer guztiak. Eta gero bizitzen zen bake handi batetan. Zeren nola herri guztietan ohi baita komunzki zenbait alfer eta iende galdu, eta hek anhitz kalte eta nahasteka egiten baitute, ontasun handia heldu zaika herriari halako heken khentzeaz. Nola lurrari ere heldu baitzaika probetxu iorratzeaz eta belhar gaixtoen atheratzeaz.

Korintioak hain zeizten aiher alferrei, ezen ikhusten zutenean gizon bat bizitzen zela errentarik gabe, ofiziorik gabe, eta trabaillatu ere gabe, berehala bertze frogantzarik gabe, bizia edekitzen baitzioten, zeren erraiten zuten ezen, presuna alfer ofiziorik eta errentarik etzuenak, ohoinkeriaz, enganamenduz edo zenbait arte gaixtoz usatu behar zuela eta halakoak bizia zor zuela, eta hala edekitzen zioten (Laert. lib.). Eta on lizate orai ere, halakoekin hala egin baledi (Axular, 31-32. orr.).

Solon handiak ordenatu zuen, ezen aita batek bere semeari ofiziorik erakusten etzioenean, etzela seme hura bere aitaren faboratzera, beharrean ikhusiagatik ere, obligatu izanen (Plutarc. in Solone.). Zeren ofiziorik ez erakusteaz, alfer eta gaixto izaiteko bidean eta perilean utzi baitzuen bere aitak. pronosticado Cipion, les sucedio (Torres, 791-792. orr.).

$\mathrm{Y}$ assi fue, que desde entonces con el descuydo, y ocio començaron las costumbres Romanas à estragarse, y à yr de mal en peor (Guzman, 63. orr.).

Ordenanos Solon, que el hijo, à quien el padre no huviesse enseñado algún oficio, y manera de vivir, no fuesse obligado à sustentarle en su vejez (Plut. In Solone. Ant Sabel. li. 6.c. 1. Cassa n. in Cat. glo. Mun. p. 11. cons. 1.); pues tan natural ley parece dexar el padre al hijo como poder vivir, como sustentar el hijo 
Gimnosophista zerizten iende batzuek hain gaitzesten zuten alferkeria, ezen bethiere, afalaitzinean deitzen baitzituzten presuna gazteak beregana, iakiteko ea zertan iragan zuten eguna, eta baldin frogatzen bazeien alferkeriarik, etzerauen afariak gaitzik egiten. (Patricius lib. de republica).

Kato. Zensorino hartzaz irakurtzen da (zeiñek baitzuen alferren gaiñean esku eta bothere) ekhartzen zeraukatenean gizon bat bere aitzinera, akusaturik, erraiten zela ezen alferra zela, berehala lehenbiziko gauza eskuetako larrua hazkatzen, eta ferekatzen zioela: eta baldin latz, lodi, eta gogor edireiten bazioen, ahalik eta arintkiena utzten zuela. Baiña mehe, leun eta bera bazuen, alfertzat kondenaturik, falta gutigatik ere bortitzki gaztigatzen zuela. (Plutarc. in vita Caton. Censor.) (Axular, 32. orr.).

Katon hark berak erraiten zuen, hirur gauzetarik, bere mendean, ahal bezanbat, begiratu zela: Emazteari bere sekeretuak fidatzetik, lehiorrez ahal zihoakeiela, itsasoz ioaitetik, eta egun guztian alfer egoitetik.

Lukanoek edireiten zutenean nehork iende alferrei deus prestatzen zeruela, emaiten zuten berehala sentenzia prestatzaillearen kontra: zerere prestatu baitzuen, hura guztia gel zezala (Nicolaus de moribus gent.). Baiña nik uste dut ezen etzela halako sentenziaren emaiteko premiarik, bera baitago emana. Zeren ezpaitu halakoei prestatzailleak, koberatzeko perilik (Axular, 32-33. orr.).

Indietako herri batzuetan, etzen bat ere bere gorputzaz balia ahal zitekeienik eskean ibiltzen. Itsuek ere tornuan edo arrodan bedere hari behar zuten. Apud Synas Indiae populos, al padre, quando tiene necesidad, y quin faltò en una ley, digno es, de que no se guarde con el otra (Guzman, 113. orr.).

De los Gymnosofistas moradores de la India, cuenta Patricio (Patri. Lib. 1. de repu. Tit. 8.), que ninguna cosa mas aborrecen, que la ociosidad, y assi acostumbran todos los dias, antes de començar à comer, llamar a los mancebos, y pedirles rigurosa cuenta de lo que aquel dia han trabajado, y obrado; y no admiten à la cena, sino à los que por su industria y trabajo lan han merecido, y ganado (Guzman, 112-113. orr.).

Y de Caton Censorino se lee, que quando sus alguaziles, y ministros prendian algun malhechor, antes de otra informacion, lo primero que le mirava era à las manos; y si las tenia de trabajados asperas, y con callos, templava el castigo; si de hombre ocioso, por pequeña culpa le dava gran pena (Aul. Gell. li.4. c.12.Vide al Licen. Castillo de Bovadilla, en su Polit. li. 2. ca. 13. que dize de todo esto) (Guzman, 114-115. orr.). 
caeci molas trusatiles versando, sibi victum parant (Osor. lib. II ${ }^{15}$ ) (Axular, 33. orr.) ${ }^{16}$.

Lehenagoko filosofo batzuek, ez aithortzeagatik egon zela behin ere Iainkoa alferrik, erran zuten, mundu haur, Iainkoa bera bezala, eterno zela eta haste gabe. Zeren bertzela mundua egin arterainoko bitartean alfer egon beharko zuela Iainkoak. Baiña ez mundua da eterno eta ez haste gabe, eta ez hargatik egotu Iainkoa egundaiño alferrik. Zeren badu, eta bazuen lehen ere Iainkoak, munduaren egitea eta gobernatzea baiño obra handiagorik: nola baitzen, eta baita, bere buruaren kontenplatzea, onhestea, eta bai bertzerik ere anhitz. Ordea filosofo hek eman zuten hartan bere ahal guztiaz aditzera gauza gaixtoa eta perilosa zela alferkeria, Iainkoa baithan edireiten zela ez aithortzeagatik, erran baitzuten erhokeria handi bat, Iainkoa bera bezala, mundua ere eterno zela eta haste gabe. Eta pontu batean, mundua haste gabe zela erraitean, huts egin bazuten ere, ordea bertzean, alfertasuna gauza gaixtoa, perilosa, eta nork bereganik egotztekoa zela erakustean, etzuten hutsik egin. Zeren hain da gauza galdua eta galgarria alferkeria, non naturalezaren beraren ere kontra baita (Axular, 33-34. orr.).

Homo nascitur ad laborem et avis ad volatum (dio Iobek) (Job. 5). Gizona sortzen da trabailluko, eta hegaztina aireko. Nola hegaztinari emaiten baitzaitza hegalak, airatzeko, eta hegaldatzeko: hala gizonari ere emaiten zaitza eskuak trabaillatzeko (Axular, 34. orr.).

Y assi dixo bien aquel amigo de Iob[...], que el hombre avia nacido condenado a trabajar, assi como el ave nacio para volar (Homo nascitur ad laborem, \& avis ad volatum. Iob 5. nu.7.) [...] Y ami parecer, y al de otro [...] que esl el del Angelico Doctor S. Tomas quiso este Filosofo dezer: que como al ave le fueron dadas alas y plumas ta a propósito, y tan proporcionadas para el buelo, assi al hombre que nacio para el trabajo, le dieron industria, instrumenos [...] (Guzman, 2. orr.).

15 Aipu guztia ez da Osoriorena, lehen lau hitzak ez baitira agertzen haren De rebus Emmanuelis 11. lib. delakoan. Beste bitartekaririk ukatu ere gabe, Zwinger-en Theatrum humanae vitae delakoan azaltzen dira hitz horiek (ikus Bilbao 2014, 161).

16 Bilbaok (2014, 160-161. orr.), argitu bezala, Zwingerrenean aurkitzen dira aurreko hiru erreferentzia horiek. Zalantza da, halere, ea Axularrek ez ote zituen gaztelaniazko debozio-libururen batetik atera. 
Munduko gauza guztiek kondenatzen dute alferra. Zeren hartzaz bertze guztiek enplegatzen baitute bere denbora, zertako eginak baitira hartan. Iguzkiak arrazoiñekin erran ahal diazaio beranduraiño ohean datzanari: zerk aratza hor alfer-nagia? Nik atzo, hik baiño bide gehiago iragan nian, inguratu bainuen mundu guztia, eta orai ere, hi baiño goizago iaiki nauk. Zuhaitzek ere erran ahal dezakete: eztakusazue nola gu ezkauden behin ere geldirik eta ez alferrik? Nola hazten, handitzen, loratzen eta geure denboretan eta sasoiñetan fruituz bethatzen garen? (Axular, 34-35. orr.).

Bada animalia adimendurik eztutenek ere, behintzat erleek eta xinhaurriek, arrazoiñekin erranen derakute, beha diazegula, heken nekeak, trabailluak eta ioan-ethorriak konsidera ditzagula eta, halatan agian, ahalketurik bedere, geure eginbidearen egitera, eta trabaillatzera, ernatuko eta erdutuko garela.

Erleak, hain gauza ttipiak, eta flakoak, bethatzen du mundua eztiz eztitzeko, eta ezkoz argitzeko. Eta gaitz lizateke kontatzea nola gobernatzen diren erleak elkharren artean; nola duten bere erregea, eta obeditzen duten; nola zaharrak kofauean barrena, etxeko lanen egiten, egoiten diren; eta gazteak, bere mantenuaren eta bizikaien garraion, kanpotik hari diren; nola duten bere athal-zaiña, eta behar ere bai. Zeren eztiari, nola baita gozo, eta izena duen bezala, ezti, anhitz, baitarraika, eta baitzaika aiher. Nola trabaillatzen direnek, trabailatzen eztiren alferrak eta nagiak, ezten kolpez egotzten dituzten bere konpaiñiatik. Expellunt ab alvearibus pigras (Plin.). Eta nola bertzerik ere anhitz gauza egiten duten, eta guztiak hain ordenantza handiarekin, non baitirudi ezen eztela erregerik, bere erresuma hain ongi gobernatzen duenik, nola erleek bere erregearekin batean trabaillatuz, gobernatzen baitute berea (Axular, 35-36. orr.).
Entre las criaturas sensibles, la solicita aveja, y la diligente ormiga dan al hombre iluste exemplo, y animo para trabajar (Guzman, 39. orr.).

[...] hablando de las avejas [...] alude el Santo Doctor [san Jeronimo] à la obediencia, y subordinación, que este bien concertado pueblo de las avejas tiene à su Rey, y à su Principe, al reves del pueblo de las ormigas, que no tiene superior [...]: pero las avejas tienen Rey, y es cosa cierto digna de admiracion, con que puntualidad sirven, con que fidelidad le defienden, [...] con el estan dentro las que le sirven de guarda, y son como sus archero, y alabarderos, sirviendoles los aguijones de puntas de lanças, para la defensa de su Rey, y de la riqueza de su miel (Guzman, 42-43. orr.).

[...] las mas ancianas [...] son las que goviernan, y guardan la casa; las mas moças salen al campo à trabajar; ay sus porteros (Guzman, 44. orr.).

Aborrecen partiularmente à los que comen [...] el pan devalde [...] Que de ver es [...] quando vemos trabajar à las avejas (Apes expellunt ab alvearibus pigras, \& non parcas. Arist. lib. 9. Plin. lib. 11. c. 10. Virgil. supra [4. Gerorg.]) [...]: verlas entrar, y salir cargadas [...] unas apartan a picadas à los que se acercan mucho a [...] sus colmenas; otras echan fuera dellos à los çanganos, y a las ociosas (Guzman, 47-48. orr.). 
Bada xinhaurriaren gobernuaz, zuhurtziaz, trabailluaz, ethorkizuneko egiten duen probisioneaz, hornizoiñaz, eta biltzen duen mantenuaz, nork zer erranen du? Nork eztu miretsiko, eta gogoeta eginen? Spiritu Sainduak berak igortzen gaitu aniamalia ttipitto hunengana, zer egin behar dugun ikhastera, erraiten duela: Vade ad formicam, o piger, et considera vias ejus, et disce sapientiam quae, cum non habeat ducem nec praeceptorem, parat in aestate cibum sibi (Prov. 6). Zoaz, nagia, xinhaurriagana, eta konsidera itzatzu haren bideak eta bidexkak, ioan-ethorriak eta itzulinguruak, nekeak eta trabailluak, eta ikhasiko duzu zuk ere nola behar duzun aitzinerat eta bethiere bizi, ibili eta gobernatu. Hark erakuslerik eta kidaririk gabe, berak bere buruz biltzen du udan, neguaren iragaiteko behar duen mantenua, bazka eta bihia (Axular, 36. orr.).

Eta bihi hura gordetzen du lurrean barrena, berak eginikako ganbaretan, eta bihi-tegietan. Eta hain da zuhur eta goithatu, ezen kanpoan deus ezin izanez, bere bilduetara bildu behar duenean, lehenik hozitu behar duen burutik hasten baitzaika bihiari: zeren bertzela sor liteke bihi hura, buztan liteke, belhar bihur liteke: eta gero handik harat, alfer-lan gertha lekidikaio bere leheneko zuhurtzia guztia.

Are gehiago, hozidurak ianez gero ere, lurraren humidurak eta hezetasunak gaiñerakoa ustel eztiazon, atheratzen du noizik behin kanporat, airatzera eta iguzkiztatzera: eta orduan denbora onaren seiñalea dateke. Eta halatan eta hala iragaiten du xinhaurriak bere negua: eta erakusten dio bat bederari nola eta zer moldez behar duen mantenatu, gobernatu eta alferkeria guztiak utzirik, bere denboran trabaillatu (Axular, 36-37. orr.).
[...] el mismo Espiritu divino, dando una vaya al pereçoso, le dize, que vaya à la ormiga, y deprenda della à trabajar: Ve pereçoso à la casa de la ormiga, y considera sus caminos, que en la dura piedra, sobre que van, y vienen, los suelen tener señalados, $y$ deprende della lo que deves hazer, la qual no teniendo Rey, ni guia, ni maestro, busca en el Estio su mantenimiento, y allega en la siega, lo que ha de comer [...] (Vade ad formicam, ò piger, \& considera vias eius, \& disce sapientiam, quae cum non habeat ducem, nec praeceptorem, nec principem, parat in Aestate cibum sibi, \& congregat inmesse, quod comedat. Prover. 6. num. 6.) (Guzman, 40. orr.).

[...] una pequeña ormiga nos da exemplo con su inmenso trabajo (Guzman, 47. orr.). 


\section{ERREFERENTZIAK}

Axular, P. (1643). Gero. Bordele: G. Millanges.

Bilbao, G. (2014). Obras de referencia latinas y otras fuentes en el Gero (1643) de Axular. In I. Arzalluz (koord.), Estudios de filología e historia en honor del profesor Vitalino Valcárcel (I. lib., 151-168 orr.). Bilbo: UPV/EHU.

González Ramírez, D. (2010). Rémoras y vagabundos en el Madrid de los Austrias. El mensaje contra la ociosidad de la Guía y avisos de forasteros (1620) entre los arbitrios de la época. Dicenda. Cuadernos de Filología Hispánica, 28, 57-72.

Guzman, P. (1614). Bienes de el honesto trabajo y daños de la ociosidad en ocho discursos. Madril: Imprenta Real.

Salaberri Muñoa, P. (1997). Axularren prosa erretorikaren argitan. Bilbo: UPV/EHU.

Salaberri Muñoa, P. (1998). Aipamen klasikoak Axularren Gero liburuan. Euskera, 43, 231-252.

Salaberri Muñoa, P. (2000). Axularren testu-zorrak. Fontes Linguae Vasconum, 84, 193-209.

Salaberri Muñoa, P. (2005). Axular Jekyll, Axular Hyde. In P. Etxeberria \& H. Knörr (konp.): Nerekin yaio nun. Txillardegiri omenaldia. Homenaje a Txillardegi. Hommage à Txillardegi. (413-430 orr.). Bilbo: UPV/EHU \& Euskaltzaindia.

Salaberri Muñoa, P. (2016). Geroren iturbegietako baten kariaz. Egan, 69-3/4, 41-88.

Terrones del Caño, F. (1617/1960). Instrucción de predicadores. Madril: Espasa-Calpe. Torres, J. (1596). Philosophia moral de príncipes. Burgos: Ph. Junta \& J. B. Varesio. 